\title{
Analisis Penerapan Cash Management System Dalam Pengelolaan Keuangan Daerah Di Pik Pulogadung
}

\author{
Imelda Sari \\ Universitas Bina Sarana Informatika/Fakultas Ekonomi dan Bisnis \\ e-mail: imelda.isx@bsi.ac.id

\begin{tabular}{ccc}
\hline Diterima & Direvisi & Disetujui \\
$11-10-2019$ & $28-11-2019$ & $09-12-2019$ \\
\hline
\end{tabular}

\begin{abstract}
Abstrak - Penelitian ini dilakukan bertujuan untuk dapat melihat pengaruh penerapan sistem manajemen kas dalam pengelolaan keuangan daerah di Unit Pengelola Kawasan Pusat Pengembangan UKM serta Permukiman Pulogadung pada periode tahun 2016-2019. Penelitian difokuskan pada variabel-variabel sistem manajemen kas meliputi pendapatan (retribusi), Belanja (pengadaan barang dan jasa) serta pengeluaran (payroll). Penelitian ini menggunakan metode deskriptif kualitatif dengan menggunakan data primer berupa objek penelitian di Unit Pengelola Kawasan Pusat Pengembangan UKM serta Permukiman Pulogadung dan data sekunder berupa teori CMS dan dokumen pendukung. Hasil penelitian ini ditemukan bahwa keseluruhan variabel independen yang digunakan dalam penerapan CMS berpengaruh secara simultan terhadap peningkatan kinerja pemerintah dan pertumbuhan ekonomi. Secara parsial penerapan CMS penerimaan retribusi, pengadaan barang dan jasa serta penggajian berpengaruh positif signifikan terhadap peningkatan kinerja pemerintah dan pertumbuhan ekonomi.
\end{abstract}

\section{Kata Kunci: Sistem Manajemen Kas, pengelolaan keuangan daerah, PIK Pulogadung}

\begin{abstract}
This research was conducted aiming to be able to see the effect of the implementation of cash management systems in the management of regional finances in the Management Unit of the small, medium enterprises. Development Center and Pulogadung Settlements in the 2016-2019 period. The study focused on cash management system variables including income (retribution), expenditure (procurement of goods and services) and expenditure (payroll). This research uses descriptive qualitative method by using primary data in the form of research objects in the Central Management Unit of the UKM Development Center and Pulogadung Settlement and secondary data in the form of CMS theory and supporting documents. The results of this study found that the overall independent variables used in the application of CMS simultaneously influence the improvement of government performance and economic growth. Partially, the application of CMS, revenue from levies, procurement of goods and services, and payroll has a significant positive effect on improving government performance and economic growth.
\end{abstract}

Keyword: Cash Management System, Regional Financial Management, Small Industrial Village Pulogadung

\section{PENDAHULUAN}

Inovasi teknologi menandai momentum transformasi di segala bidang termasuk bidang keuangan. Era digitalisasi di bidang keuangan memicu penggunaan teknologi internet, telepon pintar dan big data yang mampu menyentuh sampai ke konsumen atau pengguna akhir. Era digitalisasi keuangan mampu menciptakan kegiatan menjadi lebih efisien, baik dari segi waktu, akses maupun biaya.

Digitalisasi keuangan di pemerintahan diwujudkan dalam bentuk sebuah sistem yang disebut Cash Management System (CMS). Sistem berbasis teknologi ini bertujuan mewujudkan sistem pengelolaan keuangan daerah yang efisien dan akuntabilitas. Dasar hukum untuk melaksanakan
CMS adalah Instruksi Gubernur No. 33 Tahun 2016 tentang Pelaksanaan Transaksi Non Tunai (Gubernur Provinsi DKI Jakarta, 2016) dengan menyebutkan, untuk memantau rekening pendapatan dan belanja Satuan Kerja Perangkat Daerah/Unit Kerja Perangkat Daerah (SKPD/UKPD) dilakukan melalui sebuah system yang disebut Cash Management System (CMS). Pelaksanaannya, setiap transaksi, penerimaan maupun pengeluaran Anggaran Pendapatan dan Belanja Daerah (APBD) dilaksanakan secara non tunai (transaksi non cash). 
Grafik 1. Kinerja Pendapatan dan Penerimaan Pembiayaan

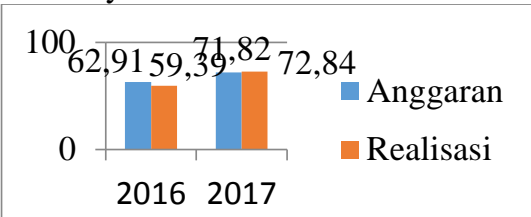

Sumber: (Pemprov, 2018)

Grafik 1. Menunjukkan Realisasi Tahun 2017

Rp 72,84 trilyun meningkat $18 \%$ atau Rp 13,45 trilyun dari Realisasi Tahun 2016 Rp 59,39 Trilyun.

Grafik 2. Kinerja Belanja dan Pengeluaran Pembiayaan

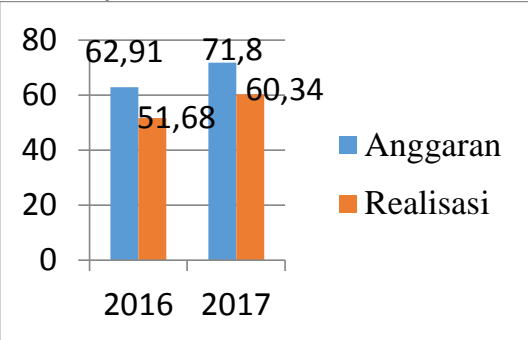

Sumber: (Pemprov, 2018)

Grafik 2. Menunjukkan Realisasi Tahun 2017 Rp 60,34 trilyun meningkat $14 \%$ atau Rp 8,66 trilyun dari Realisasi Tahun 2016 Rp 51,68 Trilyun. Kedua grafik di atas menunjukkan peningkatan realisasi Kinerja Pendapatan dan Penerimaan Pembiayaan dan Kinerja Belanja dan Pengeluaran Pembiayaan setelah diberlakukan CMS.

Penerapan CMS diperlukan untuk mempermudah proses pertanggungjawaban keuangan perangkat daerah dan mencegah resiko terjadinya penyalahgunaan keuangan di pemerintah daerah. Selain itu, sistem transaksi non tunai dianggap lebih praktis, efisien, mudah, bahkan memudahkan pelacakan. Adapun penerapan sistem non tunai ini merupakan salah satu bentuk untuk mewujudkan pengelolaan keuangan daerah yang transparan dan akuntabel.

Unit Pengelola Kawasan Pusat Pengembangan UKM serta Permukiman Pulogadung merupakan Unit Pelaksana Teknis Dinas KUKM serta Perdagangan dalam pelaksanaan pengelolaan kawasan pusat pengembangan Usaha Mikro, Kecil dan Menengah serta permukiman Pulogadung, berada di Perkampungan Industri Kecil (PIK) Pulogadung. Unit pengelola Kawasan ini, telah menerapkan CMS sejak tahun 2016. Penerapan CMS mengacu pada Instruksi Gubernur No. 33 Tahun 2016.

Unit Pengelola Kawasan menerapkan CMS dengan cara mengganti loket pendapatan (penerimaan retribusi) menjadi sistem perbankan. Pengelolaan keuangan daerah di Unit Pengelola Kawasan ada tiga, yaitu penerimaan retribusi, pengadaan barang dan jasa oleh vendor (BPK, 2013) dan penggajian untuk pegawai non PNS. Hasil penerapan CMS mampu menciptakan pengelolaan keuangan daerah menjadi lebih efisien, baik dari segi waktu, akses maupun biaya, namun demikian masih diketemukan beberapa kendala penerapannya seperti sumber daya manusia dan jaringan internet.

\section{Pengelolaan Keuangan Daerah}

Peraturan Menteri Dalam Negeri Nomor 21 Tahun 2011 (Mendagri, 2011) tentang perubahan kedua atas Permendagri Nomor 13 Tahun 2006, pasal 1 ayat (8) menjelaskan Pengelolaan keuangan daerah adalah keseluruhan kegiatan terdiri dari perencanaan, pelaksanaan, penatausahaan, pelaporan, pertanggungjawaban, dan pengawasan keuangan daerah. Peraturan tersebut meliputi kekuasaan pengelolaan keuangan daerah, azas umum dan struktur APBD, penyusunan rancangan APBD, penetapan APBD, penyusunan dan penetapan APBD bagi daerah belum ada DPRD, pelaksanaan APBD, perubahan APBD, pengelolaan kas, penatausahaan keuangan daerah, akuntansi keuangan daerah, pertanggungjawaban pelaksanaan APBD, pembinaan dan pengawasan pengelolaan keuangan daerah, kerugian daerah, dan pengelolaan keuangan BLUD.

Pengelolaan Keuangan Daerah diatur oleh Undang-Undang Nomor 23 tahun 2014 tentang Pemerintahan Daerah (Presiden, 2014). UndangUndang Nomor 23 Tahun 2014 Pasal 293 dan Pasal 330 memberikan amanat untuk mengatur Pengelolaan Keuangan Daerah dengan sebuah Peraturan Pemerintah. Peraturan Pemerintah (Presiden, 2019) mendefinisikan pengelolaan keuangan daerah yaitu keseluruhan kegiatan yang meliputi perencanaan, penganggaran, pelaksanaan, penatausahaan, pelaporan, pertanggungiawaban, dan pengawasan Keuangan Daerah.

\section{Cash Management System (CMS)}

Menurut OJK (OJK, 2016) Cash Management adalah jasa atau layanan pengelolaan kas yang diberikan kepada nasabah yang memiliki simpanan pada Bank, dimana setiap transaksi dilakukan berdasarkan perintah nasabah. Dari definisi di atas dapat diartikan Bank bertindak berdasarkan perintah nasabah (dalam hal melakukan pembayaran) dan tidak dapat bertindak sebagai agen investasi. Contoh jasa atau layanan Cash Management yang diperkenankan adalah pendebetan atau pemindahbukuan rekening nasabah dalam rangka pembayaran tagihan atau kewajiban, transfer atau pemindahbukuan dana dari satu rekening ke rekening lain milik nasabah, konsolidasi (pooling) atau distribusi dana dari kantor-kantor cabang atau jaringan operasional perusahaan, dan jasa pembayaran gaji karyawan secara massal (payroll).

Menurut Peraturan Gubernur Provinsi Daerah Khusus Ibukota Jakarta Nomor 150 Tahun 2015 (Gubernur, 2015), Cash Management System yang selanjutnya disebut CMS adalah layanan elektronik bagi nasabah korporasi (non perorangan) melalui koneksi internet dengan menggunakan browser (Internet Explorer, Fire Fox, Opera, dll) yang dapat 
dipergunakan untuk memonitor ataupun mengelola arus kas/Cash Flow secara cepat, aman, mudah dan efisien.

Bank DKI menyebutkan Cash Management System (DKI, 2019) adalah layanan perbankan berbasis internet untuk nasabah korporasi saat melakukan monitoring dan transaksi keuangan secara realtime dan online. Fasilitas ini khusus diberikan kepada nasabah Perusahaan/non-perorangan. Cash Management System Bank DKI sistem terbaru akan memudahkan perusahaan untuk mendapatkan informasi posisi dana dari waktu ke waktu dan memberikan kemudahan dalam bertransaksi melalui sistem perbankan setiap saat secara online sehingga pengelolaan arus dana dapat dilakukan secara cepat dan akurat.

CMS merupakan sebuah strategi pemerintah untuk mencegah dan memberantas korupsi, sebagai penanggung jawab strategi ini adalah Kementerian Keuangan, Kementerian Dalam Negeri dan Kementerian Hukum dan Hak Asasi Manusia. Instansi yang terkait di dalamnya adalah Bank Indonesia, Badan Pemeriksa Keuangan, Otoritas Jasa Keuangan, Pusat Pelaporan dan Analisis Transaksi Keuangan, Lembaga Kebijakan Pengadaan Barang/Jasa Pemerintah, Badan Pengawasan Keuangan dan Pembangunan, dan Pemerintah Daerah.

CMS memiliki dasar hukum terhadap tahapan implementasi transaksi non tunai di Indonesia yang cukup memadai. Undang-Undang No. 23 tahun 2014 (Presiden, 2014) Bagian keempat Pemegang Kekuasaan Pengelolaan Keuangan Daerah Pasal 283 (2), Pengelolaan keuangan Daerah sebagaimana dimaksud pada ayat (1) dilakukan secara tertib, taat pada ketentuan peraturan perundang-undangan, efisien, ekonomis, efektif, transparan, dan bertanggung jawab dengan memperhatikan rasa keadilan, kepatutan, dan manfaat untuk masyarakat. Untuk mendukung Undang-Undang tersebut, Presiden mengeluarkan Instruksi Presiden Nomor 10 Tahun 2016 (Presiden, 2016), dilanjutkan dengan dikeluarkan Pokok Surat Edaran Mendagri No. 910/1866/SJ (Mendagri, 2017).

CMS memiliki dasar hukum terhadap implementasi transaksi non tunai di Pemprov DKI Jakarta yang memadai. Instruksi Gubernur Provinsi DKI Jakarta Nomor 151 Tahun 2014 (Gubernur, 2014) tentang Pelaksanaan Transaksi Non Tunai (transaksi non cash). Peraturan Gubernur Provinsi DKI Jakarta Nomor 150 Tahun 2015 (Gubernur, 2015) tentang Perubahan atas Peraturan Gubernur Nomor 11 Tahun 2014 tentang Tata Cara Penerimaan Pembayaran Retribusi Daerah dengan Sistem Elektronik Retribusi. Instruksi Gubernur Provinsi DKI Jakarta Nomor 33 Tahun 2016 (Gubernur Provinsi DKI Jakarta, 2016) tentang Pelaksanaan Transaksi Non Tunai (Transaksi Non Cash).

CMS di PIK Pulogadung didukung dengan fasilitas perbankan berupa Kantor Cabang Pembantu
Bank DKI di kawasan PIK Pulogadung. Kondisi ini memudahkan pengusaha UMKM untuk membuka rekening dan melakukan aktifitas perbankan lainnya di Bank DKI. Bank DKI ditetapkan sebagai aggregator atau pengumpul dana dalam pelaksanaan CMS karena mampu menyediakan teknologi CMS sesuai kebutuhan Unit Pengelola Kawasan Pusat Pengembangan UMKM serta Permukiman Pulogadung.

\section{Perkampungan Industri Kecil (PIK) Pulogadung}

Salah satu lokasi UMKM yang merupakan bentukan Pemprov DKI Jakarta berada di Perkampungan Industri Kecil (PIK) Pulogadung. PIK Pulogadung merupakan salah satu sentra bisnis yang dapat dijadikan tolok ukur keberhasilan program pengembangan usaha kecil. PIK terbentuk karena unsur kesengajaan dari Pemprov DKI Jakarta pada tahun 1983. Para pengrajin atau pengusahapengusaha kecil seperti tas, sepatu, konveksi atau garmen dikumpulkan di satu tempat untuk memudahkan pembinaan dan pengontrolan terhadap para pengrajin atau pengusaha tersebut (Wiranta, 2010). Pembentukan PIK Pulogadung sebenarnya merupakan tempat relokasi home industry (industri rumahan) yang berasal dari kelurahan Palmerah dan home industri dari kawasan Pluit, Jakarta Utara di mana kawasan PIK dibangun berdasarkan kebijakan pemerintah Provinsi DKI Jakarta semasa pemerintahan Gubernur Tjokropranolo yang bertujuan untuk sentralisasi usaha/industri kecil yang diharapkan tata ruang industri di DKI Jakarta dapat tertata dengan baik. Artinya, produk home industri tidak lagi diproduksi di tengah-tengah pemukiman (Presiden, 2007).

Penelitian Juhaeriyah (Juhaeriyah, 2015) menyebutkan PIK Pulogadung terdiri dari lima sentra yaitu sentra garmen, sentra kulit, sentra mebel, sentra logam dan sentra aneka komoditi.

Grafik 3. Pendistribusian Usaha di Kawasan PIK Pulogadung

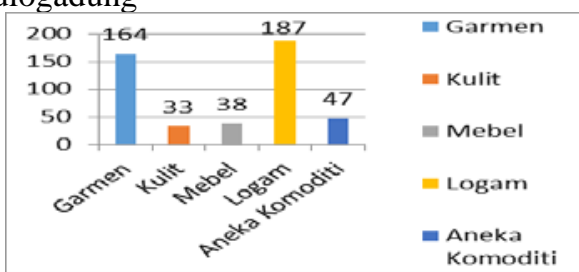

Penelitian Juhaeriyah (Juhaeriyah, 2015)

Grafik 3. memperlihatkan Sentra usaha Logam dimiliki oleh 187 usaha atau 39\% dari jumlah usaha seluruh sentra di PIK (jumlah usaha keseluruhan 469 usaha), jumlah ini terbesar bila dibandingkan dengan empat sentra usaha lainnya. Sentra usaha terkecil adalah sentra usaha Kulit dimiliki sebanyak 33 usaha atau 7\% dari jumlah usaha keseluruhan.

Peraturan Gubernur Provinsi DKI Jakarta Nomor 308 Tahun 2016 (Gubernur, 2016), 
menyebutkan bahwa PIK Pulogadung dikelola oleh Unit Pengelola Kawasan Pusat Pengembangan UKM serta Permukiman Pulogadung. Tugas Unit Pengelola Kawasan melaksanakan dan mengendalikan pengelolaan kawasan pusat pengembangan usaha mikro, kecil dan menengah serta permukiman Pulogadung. Di dalam kawasan tersebut tersedia fasilitas usaha, pemukiman dan niaga berupa: Sarana Kerja dan Hunian, Barak Kerja, Ruang Pamer, Gudang, Business Center, Permukiman, Lahan Siap Pakai, dan Fasilitas Usaha lainnya. Selain itu, didalam Kawasan PIK Pulogadung juga dilengkapi dengan fasilitas pendukung berupa: Fasilitas Pendidikan (SD dan SMP), Fasilitas Kesehatan (Puskesmas), Fasilitas Keamanan (Pos Polisi), Fasilitas Kemasyarakatan (Kantor Lurah), Fasilitas Pemadam Kebakaran, Fasilitas Perbankan (Bank DKI), Fasilitas Kebersihan, Sarana Fasilitas (Telepon, Air, dan Listrik).

\section{METODE PENELITIAN}

Jenis Penelitian ini adalah jenis penelitian deskritif kualitatif. Penelitian deskritif kualitatif ini bertujuan untuk memperoleh informasi keadaan yang terjadi saat penelitian berlangsung dengan menyuguhkan apa yang sebenarnya terjadi. Peneliti Moleong (Moleong, 2014) menyebutkan, penelitian kualitatif adalah penelitian yang bermaksud untuk memahami tentang apa yang dialami oleh subjek penelitian, misalnya: perilaku, persepsi, dan motivasi. Lokasi penelitian di Unit Pengelola Kawasan Pusat Pengembangan UKM serta Permukiman Pulogadung.

Jenis dan Sumber Data. Dalam penelitian ini peneliti memakai jenis data kualitatif. Sumber data yang digunakan ada 2 yaitu data primer dan data sekunder. Sumber data primer yang diperoleh langsung dari objek penelitian di Unit Pengelola Kawasan Pusat Pengembangan UKM serta Permukiman Pulogadung melalui wawancara dan observasi langsung. Sumber data sekunder dari buku dan internet.
Metode Pengumpulan Data. Data dalam penulisan penelitian ini dikumpulkan dengan menggunakan metode:

1. Wawancara. Wawancara merupakan teknik pengumpulan data dengan cara mengajukan pertanyaan-pertanyaan kepada pihak-pihak yang terkait dengan penelitian.

2. Observasi. Metode ini digunakan untuk mempelajari secara langsung kesiapan dan proses penerapan cash management system dalam pelaksanaan anggaran pada objek penelitian serta untuk mengetahui keakuratan data dengan membandingkan hasil wawancara dengan keadaan sebenarnya.

3. Studi Pustaka. Metode ini digunakan untuk memperoleh data mengenai teori-teori atau dokumen-dokumen yang terkait dengan proses penerapan cash management system dalam pengelolaan keuangan daerah di Unit Pengelola Kawasan Pusat Pengembangan UKM serta Permukiman Pulogadung.

Metode Analisis Data adalah proses mencari dan menyusun secara sistematis data yang diperoleh dari wawancara, catatan lapangan, dan dokumentasi, dengan cara mengorganisasikan data ke dalam kategori, menjabarkan ke dalam variabel-variabel, melakukan sintesa, menyusun ke dalam pola, memilih mana yang penting dan yang akan dipelajari, dan membuat kesimpulan sehingga mudah dipahami oleh diri sendiri maupun orang lain (Sugiyono, 2016). Penelitian ini menggambar atau menganalisis suatu hasil penelitian tetapi tidak digunakan untuk membuat kesimpulan yang lebih luas, disebut dengan metode deskriptif yang digunakan dalam penelitian ini.

\section{HASIL DAN PEMBAHASAN}

\section{Hasil Penelitian}

Perekonomian Indonesia saat ini terus mengalami peningkatan, hal ini dilihat dari Produk Domestik Bruto (PDB) atas dasar harga berlaku dan PDB atas dasar harga konstan.

Grafik 4. PDB Atas Dasar Harga Berlaku dan Konstan (Seri 2010) Tahun 2014-2019 (Milyar Rupiah)

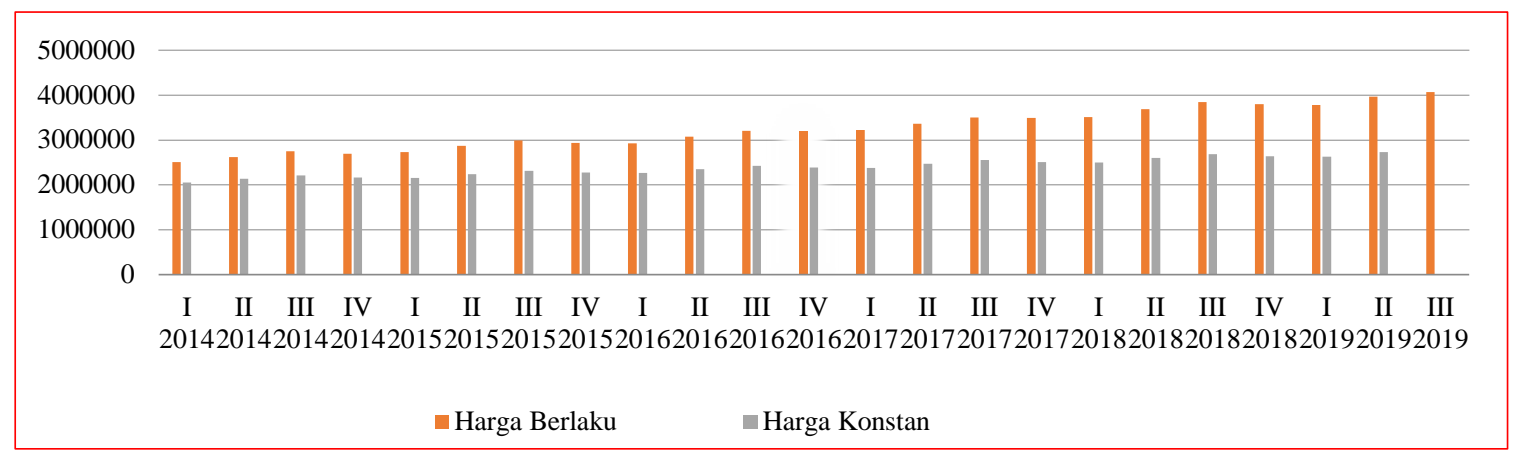

Sumber: (BPS, 2019) 
Grafik 4. Grafik diatas menjelaskan perekonomian Indonesia dilihat dari triwulanan dalam kurun waktu 2014-2019 yang diukur berdasarkan Produk Domestik Bruto (PDB) atas dasar harga berlaku dan PDB atas dasar harga konstan yang menunjukkan trend meningkat. Nilai PDB atas dasar harga berlaku triwulanan cenderung meningkat dari triwulan I setiap tahun sampai dengan triwulan III, dan mengalami sedikit menurun pada triwulan IV dibanding triwulan sebelumnya. Hal yang sama juga terjadi pada PDB atas dasar harga konstan.

Perekonomian Indonesia berdasarkan besaran PDB atas dasar harga berlaku triwulan III-2019 mencapai Rp 4.067,8 triliun dan atas dasar harga konstan 2010 mencapai Rp 2.818,9 triliun. Usaha Mikro, Kecil dan Menengah (UMKM) memiliki peran penting dan strategis dalam pembangunan ekonomi nasional di Indonesia dan memberikan sumbangan terbesar. Selain berperan dalam pertumbuhan ekonomi dan penyerapan tenaga kerja, UMKM juga berperan dalam mendistribusikan hasilhasil pembangunan. Menurut Indrawan (Indrawan, 2019) kontribusi UMKM pada PDB sebesar 60\% dan tingkat penyerapan tenaga kerja sekitar 97\% dari seluruh tenaga kerja nasional.

Grafik 5. Perkembangan Data UMKM Tahun 20122017

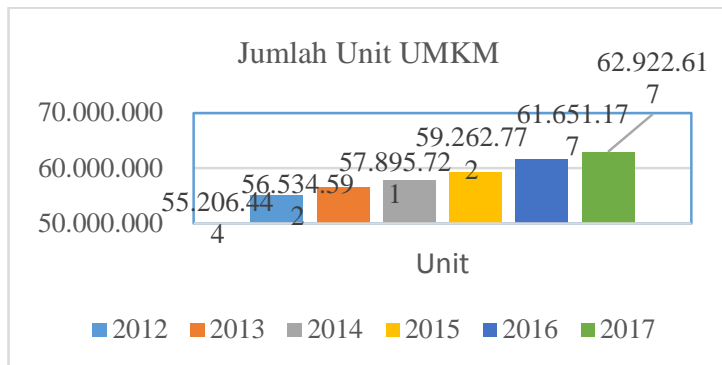

Sumber : (BPS, 2018)

Grafik 5. memperlihatkan jumlah unit UMKM naik setiap tahun secara signifikan. Tahun 2012 sampai tahun 2015 jumlah unit UMKM mengalami peningkatan 2\% setiap tahun. Tahun 2016 jumlah unit UMKM mengalami peningkatan $4 \%$ dari tahun sebelumnya. Grafik ini menunjukkan bahwa peluang UMKM sangat potensial untuk dibina dan dikembangkan. Pengusaha UMKM di PIK Pulogadung, pegawai Non PNS dan rekanan di kantor Unit Pengelola Kawasan Pusat Pengembangan UKM serta Permukiman Pulogadung berjumlah cukup banyak, kondisi ini mampu menciptakan peluang bagi perkembangan CMS di Indonesia.

UMKM di PIK dikenakan retribusi sebagai pembayaran atas jasa atau pemberian ijin tertentu yang khusus disediakan dan/atau diberikan oleh pemerintah daerah untuk kepentingan orang pribadi atau badan, baik yang bersifat pelayanan jasa umum, pelayanan jasa usaha dan perijinan tertentu (Gubernur, 2019). Pungutan retribusi ini merupakan bagian dari keuangan daerah yang penerapannya menggunakan CMS. Pengelolaan keuangan daerah yang lainnya adalah pengadaan barang dan jasa (dengan vendor) serta pemberian gaji untuk pegawai non PNS Unit Pengelola Kawasan.

\section{Pembahasan}

1. Pengelolaan Keuangan Daerah di Unit Pengelola Kawasan Pusat Pengembangan UKM serta Permukiman Pulogadung, untuk penerimaan Retribusi, pelaksanaannya sebagai berikut (Kemendagri, 2017):

- Pengguna Anggaran menyerahkan Surat Ketetapan Retribusi (SKR) kepada Wajib Retribusi dan Bendahara Penerimaan;

- Wajib Retribusi membayarkan uang kepada Bank DKI sejumlah yang tertera di SKR.

- Bank DKI menerbitkan slip setoran/bukti lain yang sah dan nota kredit;

- Bank DKI menyerahkan slip setoran kepada wajib retribusi dan Nota Kredit kepada Bendahara Umum Daerah (BUD);

- Wajib retribusi menyerahkan slip setoran yang sah kepada Bendahara Penerimaan.

Mengacu pada pelaksanaan CMS di atas, akan memudahkan dan menghemat waktu wajib retribusi yaitu pengusaha PIK Pulogadung saat membayar retribusi ke kantor Unit Pengelola Kawasan Pusat Pengembangan UKM serta Permukiman Pulogadung. Bendahara Unit Pengelola Kawasan dapat memantau langsung data transaksi Wajib Retribusi secara real time, sehingga bisa mengetahui pendapatan daerah dari retribusi. Tugas bendahara dipermudah dalam penagihan retribusi karena sebagian penagihannya sudah langsung dibayarkan oleh wajib retribusi lewat bank atau rekening. Hasil yang diperoleh ini sama dengan penelitian Kamal (Kamal, 2016).

2. Pengelolaan Keuangan Daerah Unit Pengelola Kawasan Pusat Pengembangan UKM serta Permukiman Pulogadung, untuk pengeluaran pembiayaan Pengadaan Barang dan Jasa oleh Vendor, pelaksanaannya sebagai berikut (Kemendagri, 2017):

- Pejabat Pelaksana Teknis Kegiatan (PPTK) menyiapkan dokumen;

- PPTK menyerahkan Surat Permintaan Surat Permintaan Pembayaran Langsung, yang selanjutnya disingkat SPP-LS, adalah dokumen permintaan pembayaran yang dibuat/diterbitkan oleh PPK yang dibayarkan langsung kepada Bendahara Pengeluaran/ Penerima Hak atas dasar kontrak kerja, surat keputusan, surat tugas atau surat perintah kerja lainnya;

- Bendahara Pengeluaran ke Pejabat Penatausahaan Keuangan (PPK SKPD);

- PPK SKPD ke Pejabat Pengguna Anggaran/Kuasa;

- Pejabat Pengguna Anggaran/Kuasa memberikan Surat Perintah Membayar (SPM), memberikan kuasa kepada Bendahara Umum Daerah (BUD); 
- BUD mengeluarkan Surat Perintah Pencairan Dana (SP2D) yang merupakan surat perintah yang diterbitkan oleh Kantor Pelayanan Perbendaharaan Negara (KPPN) selaku Kuasa Bendahara Umum Negara untuk pelaksanaan pengeluaran atas beban APBN berdasarkan SPM untuk diserahkan ke bank;

- Pihak ketiga (vendor) menerima uang non tunai melalui transfer ke rekening.

Pelaksanaan CMS untuk pengeluaran pembiayaan pengadaan barang dan jasa oleh vendor berdampak positif karena penggunaan aliran dana seluruh transaksi dapat ditelusuri, dikarenakan seluruh transaksi didukung dengan bukti yang sah. Bendahara tidak harus memegang uang tunai dengan berbagai resiko kejahatan, kehilangan, dan kesalahan hitung. Manfaat CMS ini sama dengan penelitian Pelealu (Pelealu, 2018).

Vendor sebagai penyedia barang/jasa, harus memiliki rekening bank, No NPWP, mau mengikuti Standard Operation Procedure (SOP) pembayaran pemda, dan sesuai mekanisme pengadaan. Pelaksanaan CMS untuk pengadaan barang dan jasa, memberikan kemudahan aplikasi (user friendly) yang mudah dipahami semua pihak, kecepatan layanan dan penghematan waktu bagi vendor (rekanan) dalam pengadaan barang dan jasa. CMS mampu meningkatkan produktivitas bisnis vendor, hal ini menciptakan peluang pelaku usaha untuk dapat melakukan pelacakan aliran transaksi lebih valid.

3. Pengelolaan Keuangan Daerah Unit Pengelola Kawasan Pusat Pengembangan UKM serta Permukiman Pulogadung, belanja untuk Pembayaran gaji bagi pegawai Unit Pengelola Kawasan Non PNS pelaksanaannya sebagai berikut (Kemendagri, 2017):

- Bendahara mengunggah data rekening pegawai yang berisi nama, nomor rekening dan nominal;

- Data file penggajian terdiri dari : tanggal transaksi (tanggal dilakukannya auto debet) dan rekening sumber (rekening yang digunakan untuk melakukan auto debet;

- Upload file yang terdiri dari: nomor referensi, nomor rekening, nama pemilik rekening dan nominal gaji yang akan ditransfer.

Penerapan CMS memberikan kemudahan aplikasi (user friendly) yang mudah dipahami semua pihak, kecepatan layanan dan penghematan waktu bagi pegawai Non PNS Unit Pengelola Kawasan saat menerima gaji bulanan. Perintah pembayaran gaji pegawai non PNS Unit Pengelola Kawasan dilaksanakan secara berjadwal setiap bulan dan berlaku realtime setelah dilakukannya otorisasi transaksi, yaitu data nama dan nomor rekening pegawai non PNS akan diverifikasi secara otomatis oleh sistem untuk menghindari kesalahan transfer. CMS memudahkan pegawai non PNS Unit Pengelola
Kawasan Pusat Pengembangan UKM serta Permukiman Pulogadung menerima gaji tepat waktu dan tercatat.

Bank DKI memiliki Virtual Account untuk kemudahan melakukan identifikasi penerimaan pembayaran perusahaan dengan cara yang mudah dan informasi yang lengkap dengan keterangan sebagai berikut:

a. Dana penerimaan secara realtime akan terkredit ke rekening perusahaan;

b. Adanya fasilitas cut off time untuk menghitung jumlah total dana keseluruhan penerimaan perusahaan untuk di kreditkan secara langsung ke rekening utama perusahaan;

c. Tipe Pembayaran flexible yang dapat dipilih sesuai dengan kebutuhan (fix payment/close payment atau open payment);

d. Nomor Virtual Account langsung dapat diaktifkan;

e. Memiliki jaringan pembayaran yang luas : ATM Bank DKI, ATM Bank Lain, Mobile Banking, SKN-RTGS dan E-channel bank lain yang tergabung dalam jaringan ATM Bersama \& ATM Prima.

Pelaksanaan CMS, selain banyak keuntungan ada juga kendala yang terjadi. Di bawah ini beberapa kendala yang masih terjadi, yaitu

a. Fasilitas cut off time sangat bermanfaat untuk mengetahui total penerimaan retribusi. Fasilitas ini tidak dapat digunakan bila jaringan koneksi internet mengalami hambatan atau gangguan, menyebabkan Bendahara kesulitan mendapatkan data penerimaan retribusi secara cepat dan realtime. Untuk meminimalisir kejadian tersebut, perlu dilakukan pengecekan rutin jaringan internet serta penambahan daya untuk mendukung jaringan. Penelitian Windu (Windu, 2018) menyebutkan seringnya terjadi masalah jaringan untuk mengakses internet, diperlukan campur tangan pihak bank berinovasi untuk perbaikan kualitas system yang lebih baik.

b. Tingkat pengetahuan sebagian pengusaha UMKM PIK Pulogadung terhadap teknologi finansial yang relatif rendah berdampak tidak maksimal dalam mengakses layanan keuangan perbankan. Untuk meningkatkan pengetahuan pengusaha UMKM PIK Pulogadung, diperlukan sosialisasi yang rutin dan menyeluruh terhadap teknologi financial.

c. Bagi pengusaha Mikro dengan pendapatan yang masih minim, adanya potongan atau biaya administrasi bulanan di rekening bank yang dimiliki agak memberatkan pengusaha tersebut. Untuk meningkatkan pendapatan pengusaha dengan tingkat pendapatan minim, Unit Pengelola Kawasan memberikan dukungan berupa promosi produk pengusaha tersebut, memberikan pelatihan dan membantu ketersediaan peralatan kerja. 
d. Faktor risiko keamanan data pemilik rekening yang dapat disalahgunakan oleh pihak yang tidak bertanggung jawab. Bank DKI harus mampu menyediakan perangkat keamanan yang kuat serta pengawasan yang terus menerus.

\section{KESIMPULAN}

Dari hasil penelitian ini disimpulkan bahwa pelaksanaan cash management system di PIK Pulogadung mampu menciptakan pengelolaan keuangan daerah menjadi lebih efisien, baik dari segi waktu, akses maupun biaya. Kemudahan wajib retribusi membayar retribusi, kemudahan vendor saat pengadaan barang dan jasa, serta kemudahan penggajian pegawai non PNS Unit Pengelola Kawasan mampu membawa manfaat bagi pelaku usaha dan peningkatan kinerja ekonomi.

Peningkatan CMS berdampak pada penurunan uang palsu, menghemat pengeluaran Negara dan mencegah transaksi illegal (korupsi). Hal ini menyebabkan peningkatan kinerja ekonomi di Unit Pengelola Kawasan Pusat Pengembangan UKM serta Permukiman Pulogadung serta peningkatan output riil nasional.

\section{REFERENSI}

BPK. (2013). Sosialisasi Program Non Cash Transaction di Balaikota Pemprov DKI Jakarta. Retrieved from https://jakarta.bpk.go.id/?p=3056

BPS. (2018). Perkembangan Data Usaha Mikro, Kecil dan Menengah (UMKM) dan Usaha Besar (UB) Tahun 2012-2017.

BPS. (2019). [Seri 2010] PDB Triwulanan Atas Dasar Harga Berlaku Menurut Lapangan Usaha (Miliar Rupiah), 2014-2019. Retrieved from

https://www.bps.go.id/dynamictable/2015/05/0 6/826/-seri-2010-pdb-triwulanan-atas-dasarharga-berlaku-menurut-lapangan-usaha-miliarrupiah-2014-2019.html

DKI, B. (2019). Tindak Lanjut Rencana Aksi Keuangan Berkelanjutan.

Gubernur. INSTRUKSI GUBERNUR PROVINSI DAERAH KHUSUS IBUKOTA JAKARTA NOMOR 151 TAHUN 2014 TENTANG PELAKSANAAN TRANSAKSI NON TUNAl (TRANSAKSI NON-CASH), Pub. L. No. NOMOR 151 TAHUN 2014 (2014).

Gubernur. Peraturan Gubernur Provinsi DKI Jakarta Nomor 150 Tahun 2015 tentang Perubahan Atas Peraturan Gubernur Nomor 11 Tahun 2014 Tentang Tata Cara Penerimaan Pembayaran Retribusi Daerah dengan Sistem Elektronik Retribusi, Pub. L. No. Nomor 150 Tahun 2015 (2015).

Gubernur. PERATURAN GUBERNUR PROVINSI
DAERAH KHUSUS IBUKOTA JAKARTA NOMOR 308 TAHUN 2016 TENTANG PEMBENTUKAN, ORGANISASI DAN TATA KERJA UNIT PENGELOLA KAWASAN PUSAT PENGEMBANGAN USAHA KECIL DAN MENENGAH SERTA PERMUKIMAN PULOGADUNG, Pub. L. No. NOMOR 308 TAHUN 2016 (2016). Retrieved

from https://jdih.jakarta.go.id/uploads/default/produ khukum/PERGUB_NO.308_TAHUN_.2016_. pdf

Gubernur. (2019). Laporan Keuangan Pemerintah Daerah Provinsi DKI Jakarta Tahun Anggaran 2018. Jakarta.

Gubernur Provinsi DKI Jakarta. Instruksi Gubernur Provinsi DKI Jakarta No. 33 Tahun 2016 Tentang Pelaksanaan Transaksi Non Tunai (Transaksi Non-Cash), Pub. L. No. Nomor 33 Tahun 2016 (2016).

Indrawan, R. (2019). Sinergitas Pengembangan KUMKM melalui Penguatan Peran Antar Lembaga Disampaikan dalama cara: Rapat Kerja Nasional. Sanur, Bali. Retrieved from http://www.depkop.go.id/uploads/laporan/156 6564351_Bahan Paparan SESMENEGKOP Sinergitas Pengembangan KUMKM melalui Penguatan Peran Antar Lembaga.pdf

Juhaeriyah, S. K. dan K. (2015). Pengaruh Pelatihan dan Kreatifitas Terhadap Pengembangan Usaha pada Usaha Kecil dan Menengah di Perkampungan Industri Kecil Pulogadung Jakarta Timur. Econo Sains, Academia.Edu, 113. Retrieved from https://www.academia.edu/attachments/45315 954/download_file?st=MTU2OTA4MTk0NS wxMTUuMTc4LjIyMS42OCwxMTc2NDE1 ODU\%3D\&s=swp_related_works_sidebar

Kamal, F. (2016). Analisis Pembayaran Pajak Hiburan dengan Menggunakan Cash Management System (Studi Kasus pada PT Firdaus Jakarta). Media Akuntansi Perpajakan, 1(1), 75-83. Retrieved from http://journal.uta45jakarta.ac.id/index.php/MA $\mathrm{P} /$ article/view/168

Kemendagri. (2017). Implementasi Transaksi Non Tunai. Kendari.

Mendagri. MENTERI DALAM NEGERI REPUBLIK INDONESIA PERATURAN MENTERI DALAM NEGERI NOMOR 21 TAHUN 2011 TENTANG PERUBAHAN KEDUA ATAS PERATURAN MENTERI DALAM NEGERI NOMOR13 TAHUN 2006 TENTANG PEDOMAN PENGELOLAAN KEUANGAN DAERAH, Pub. L. No. NOMOR 21TAHUN 2011 (2011). Retrieved from

https://bapenda.jabarprov.go.id/JDIH/Peratura n_Mendagri/PERATURAN_MENTERI_DAL AM_NEGERI_NOMOR_21_TAHUN_2011.p 
$\mathrm{df}$

Mendagri. Menteri Dalam Negeri Republik Indonesia Surat Edaran Nomor 910/1866/SJ tentang Implementasi Transaksi Non Tunai pada Pemerintah Daerah Provinsi, Pub. L. No. SE Nomor 910/1866/SJ (2017).

Moleong, L. J. (2014). Metodologi Penelitian Kualitatif. Bandung: PT Remaja Rosdakarya.

OJK. SURAT EDARAN OTORITAS JASA KEUANGAN NOMOR 27/SEOJK.03/2016 TENTANG KEGIATAN USAHA BANK UMUM BERDASARKAN MODAL INTI, Pub. L. No. NOMOR 27/SEOJK.03/2016 (2016). Retrieved from https://www.ojk.go.id/id/kanal/perbankan/regu lasi/surat-edaran-ojk/Documents/LampiranSEOJK-Mutlicense.pdf

Pelealu, A. G. B. dan N. (2018). Analisis Penerapan Sistem Transaksi Non Tunai Dalam Pengelolaan Keuangan Daerah pada Dinas Lingkungan Hidup Kota Bitung. Jurnal Riset Akuntansi, 13(4), 220-229. Retrieved from https://ejournal.unsrat.ac.id/index.php/gc/articl e/view/21018

Pemprov, J. (2018). Implementasi Transaksi Non Tunai Dalam Peningkatan Akuntabilitas Pengelolaan Keuangan Daerah. Retrieved from

http://keuda.kemendagri.go.id/asset/kcfinder/u pload/files/BPKAD DKI Jakarta.pdf

Presiden. UNDANG-UNDANG REPUBLIK INDONESIA NOMOR 26 TAHUN 2007 TENTANG PENATAAN RUANG, Pub. L. No. NOMOR 26 TAHUN 2007 (2007). Retrieved from https://www.gitews.org/tsunami-

kit/en/E6/further_resources/national_level/und ang_undang/UU 26-2007_Penataan Ruang.pdf

Presiden. UNDANG-UNDANG REPUBLIK INDONESIA NOMOR 23 TAHUN 2014 TENTANG PEMERINTAHAN DAERAH, Pub. L. No. UU RI Nomor 23 Tahun 2014 (2014). Retrieved from https://pih.kemlu.go.id/files/UU0232014.pdf

Presiden. Instruksi Presiden Republik Indonesia Nomor 10 Tahun 2016 tentang Aksi Pencegahan dan Pemberantasan Korupsi Tahun 2016 dan Tahun 2017, Pub. L. No. Nomor 10
Tahun 2016 (2016). Retrieved from http://www.jdih.setjen.kemendagri.go.id/pm/I NPRES No.10 TH 2016.pdf

Presiden. PERATURAN PEMERINTAH REPUBLIK INDONESIA NOMOR 12 TAHUN 2019 TENTANG PENGELOLAAN KEUANGAN DAERAH, Pub. L. No. Nomor 12 tahun 2019 (2019). Retrieved from https://sipuu.setkab.go.id/PUUdoc/175801/PP _Nomor_12_Tahun_2019.pdf

Sugiyono. (2016). Metodologi Penelitian Kuantitatif, Kualitatif, dan R\&D. Bandung: CV. Alfabeta.

Windu, D. S. W. dan F. S. (2018). Analisis Efektivitas Penerapan Cash Management System (CMS) dalam Meningkatkan Value Added System pada Bank Rakyat Indonesia Cabang Madiun. Prosiding FIPA ( Forum Ilmiah Pendidikan Akuntansi), 6(2). Retrieved from http://prosiding.unipma.ac.id/index.php/FIPA/ article/view/546

Wiranta, S. (2010). Pemasaran Produk-Produk UKM PIK (Pusat/Perkampungan Industri Kecil) Pulo Gadung. Buletin Ilmiah Litbang Perdagangan, 4(2), 240-255. Retrieved from http://paper.researchbib.com/view/paper/14804 0

\section{PROFIL PENULIS}

Imelda Sari, S.I.P., M.E., adalah alumni dari Universitas Indonesia, Depok tahun 2008, dari Program Studi Magister Perencanaan dan Kebijakan Publik. Saat ini aktif sebagai Dosen dan menjadi bagian di Unit Pengembang Akademik pada program studi Manajemen di Fakultas Ekonomi dan Bisnis Universitas Bina Sarana Informatika. Aktif sebagai Asesor bidang Manajemen Bisnis dan kewirausahaan dan telah mengikuti tiga sertifikasi kompetensi BNSP yaitu Kewirausahaan Industri, Pelaksanaan Pemasaran dan Pendamping Kewirausahaan. Tercatat sebagai anggota Asosiasi Dosen Indonesia (ADI), anggota Keluarga Alumni Gadjah Mada (KAGAMA) dan anggota Ikatan Ilmuwan Indonesia Internasional (I-4). Selain itu aktif mengikuti kegiatan seminar, workshop baik yang bersifat lokal kampus, nasional dan internasional. Penelitian yang dilakukan terkait dalam bidang ekonomi. 